Postprint: Jacek Chwast, Jelena Todorović, Hans Janssen, Jan Elsen, Gypsum efflorescence on clay brick masonry: Field survey and literature study, Construction and Building Materials, Volume 85, 15 June 2015, Pages 57-64, http://dx.doi.org/10.1016/j.conbuildmat.2015.02.094

\title{
Gypsum efflorescence on clay brick masonry: Field survey and literature study
}

Jacek Chwast $^{(1)}$, Jelena Todorović ${ }^{(2)}$, Hans Janssen ${ }^{(2)}$ and Jan Elsen ${ }^{(1)}$

(1) KU Leuven, Department of Earth and Environmental Sciences, Celestijnenlaan 200E, 3001

Leuven, Belgium - jacek.chwast@ees.kuleuven.be; jan.elsen@ees.kuleuven.be

(2) KU Leuven, Department of Civil Engineering, Kasteelpark Arenberg 40, 3001 Leuven, Belgium - jelena.todorovic@bwk.kuleuven.be; hans.janssen@bwk.kuleuven.be

\begin{abstract}
Belgian masonry facades are being increasingly affected by unsightly persistent efflorescence. This results in disappointed customers and consequently creates a threat for the brick industry. Our paper presents a field survey and literature review on the topic. An investigation of Belgian cases reveals an abundance of gypsum in the deposits. The specific characteristics and literature review indicate masonry as the source and moisture transfer as the transport mechanism. However, there is currently no sound explanation for the relatively recent occurrence of gypsum crystallization on the surface. One hypothesis points at mortar additives, which may affect the transport and crystallisation of gypsum.
\end{abstract}

\section{Keywords}

Gypsum, efflorescence, masonry

\section{Introduction}

Salt efflorescence, the growth of salt crystals on a surface caused by evaporation of salt-laden water, is a typical surface defect commonly observed on brick, mortar and concrete facades. Mostly, 
Postprint: Jacek Chwast, Jelena Todorović, Hans Janssen, Jan Elsen, Gypsum efflorescence on clay brick masonry: Field survey and literature study, Construction and Building Materials, Volume 85, 15 June 2015, Pages 57-64, http://dx.doi.org/10.1016/j.conbuildmat.2015.02.094

it concerns whitish deposits of water soluble salts, like alkali sulphates or sodium chloride, which generally appear soon after erection of the facade. Due to their high solubility, these salts are easily brought to the facade's surface via moisture flow, and they are similarly easily washed away from the surface by natural weathering. Since the 1980's however, a grey-white efflorescence has started appearing on a number of clay brick masonry facades, in the UK, in the Netherlands as well as in Belgium, with a particular gypsum-rich efflorescence (Bowler and Winter 1996; H. Brocken and Nijland 2004). This specific efflorescence type usually appears a couple of years after construction. The main efflorescence constituent is slightly soluble gypsum, that explains its persistence against natural weathering. The field survey and literature review presented in this paper are motivated by the progressively growing number of gypsum efflorescence (GE) cases reported in Belgium. The paper aims at setting the stage for further research into the potential causes and possible solutions for this growing problem of aesthetic deficiency. The field survey confirms the occurrence of gypsum efflorescence; the literature review reveals the complexity of the underlying processes.

From their investigations of ten gypsum efflorescence cases in the UK, Bowler and Winter (1996) deduced a number of crucial observations. Firstly, it is a recent phenomenon, appearing only since the 1980's, solely affecting newly erected facades. Older facades constructed with similar bricks do not suffer from such surface staining. Moreover, this staining is commonly only perceived after a number of years, contrary to the earlier efflorescence of more soluble salts. Gypsum efflorescence furthermore mainly affects facades with a high wind-driven rain load, and these facades often but not always - comprise cavity insulation. There is no clear relation with the brick type however, as gypsum efflorescence is observed on bricks with both low and high sulphate contents.

Although calcium sulphate is one of the major salts present in building materials (Charola, Pühringer, and Steiger 2006), it is commonly believed that, due to its very low solubility, its presence in bricks does not lead to efflorescence or sulphate attack (Bowler and Fischer, 1989). Steiger and Heritage (2012) similarly noted that gypsum is considered fairly inactive with respect 
Postprint: Jacek Chwast, Jelena Todorović, Hans Janssen, Jan Elsen, Gypsum efflorescence on clay brick masonry: Field survey and literature study, Construction and Building Materials, Volume 85, 15 June 2015, Pages 57-64, http://dx.doi.org/10.1016/j.conbuildmat.2015.02.094

to changes in $\mathrm{RH}$ and temperature, hence not undergoing phase transitions, and therefore not likely to cause damage like other salts. These are the main reasons for the lack of research activity on gypsum in porous materials. Consequently, even though gypsum efflorescence has been occurring for some decades, the physico-chemical processes behind this phenomenon are still unclear. This paper therefore has a double objective. The reported field survey establishes the occurrence of gypsum efflorescence in Belgium and confirms and widens the earlier observations by Bowler and Winter (1996) and Brocken and Nijland (2004). The presented literature review gathers the current knowledge in relation to gypsum efflorescence, and formulates the main research questions to be tackled in order to come to further insight in this phenomenon.

The field survey investigates 28 cases of persistent efflorescence on brick masonry. It confirms that the main component often is slightly soluble gypsum, explaining their persistent nature. For most cases, the brick type is identified, and potential relations between brick properties and efflorescence formation are analysed. Based on our data, neither the brick's hygric characteristics, nor its sulphate content appear to be significant for the formation of gypsum efflorescence. The literature review assesses different physico-chemical processes potentially underlying this phenomenon. These include mortar and brick as potential sources of gypsum, the dissolution, transport and crystallization of gypsum, and the recent changes undergone by masonry as potential triggers for gypsum efflorescence. Based on the information collected via the field study and literature review, we conclude this paper by formulating the most essential research questions related to the gypsum efflorescence phenomenon.

\section{Field Survey on persistent efflorescence}

Persistent efflorescence - stains of slightly soluble salts that do not wash off naturally - is a growing problem in the construction industry. Besides the occurrence in the UK and the Netherlands (Bowler and Winter 1996; H. Brocken and Nijland 2004), the Belgian brick produ- 
Postprint: Jacek Chwast, Jelena Todorović, Hans Janssen, Jan Elsen, Gypsum efflorescence on clay brick masonry: Field survey and literature study, Construction and Building Materials, Volume 85, 15 June 2015, Pages 57-64, http://dx.doi.org/10.1016/j.conbuildmat.2015.02.094

cers are receiving progressively more complaints, as building owners blame their products for the flaw. In the opinion of the Belgian brick producers, persistent efflorescence occurs more frequently, develops quicker than before, and gets more pronounced over time.

In order to contribute to the knowledge on this issue a field survey is carried out, to determine the major factors associated with its occurrence. In this survey, 28 cases of Belgian buildings affected by persistent efflorescence are analysed. Some of these cases were identified from the complaints of building owners to brick producers, other cases were found during an exploration of the Leuven area in Belgium by the researchers.

\subsection{General observations on persistent efflorescence}

The investigated cases concern a type of permanent efflorescence, which after having developed on a masonry surface does not wash off with natural weathering. In two cases the building facades had been cleaned with high-pressure water jets, which removed the efflorescence stains temporarily, but did not restore the facades' original appearance. In both cases efflorescence has reappeared, indicating that the efflorescence source is not affected by the treatment. The observed persistent efflorescences come in different appearances, ranging from a thin whitish veil present within the porous surface of a material to a locally developed thicker crust on top of the material's surface. Even while being thin and hazy from an up-close perspective, the efflorescence greatly alters the aesthetic aspect of the masonry facade when looking from a distance (see Figure 1). In contrast to early efflorescences of easily soluble salts, often being soft and thick, these persistent efflorescences give the impression of being very compact and strongly adhering to the brick surface, while simultaneously generally being very thin. In most cases the efflorescence affects the bricks to a much greater extent than the mortar joints.

The building facades are all constructed with mechanically produced 'hand' moulded clay bricks, most commonly used for facade masonry in Belgium. In all cases, the most affected facades of the building are those oriented West to South, with efflorescence being most pronounced on the edges 
Postprint: Jacek Chwast, Jelena Todorović, Hans Janssen, Jan Elsen, Gypsum efflorescence on clay brick masonry: Field survey and literature study, Construction and Building Materials, Volume 85, 15 June 2015, Pages 57-64, http://dx.doi.org/10.1016/j.conbuildmat.2015.02.094

and the upper parts of the façade, façade orientations and locations that typically receive relatively frequent wind-driven rain.

The year of construction is known for 15 of the 28 cases, and ranges from 1997 to 2007. The other cases are probably constructed in a similar period, as they have an equally modern appearance. None of the 28 studied cases hence concerns older constructions, and the problem thus appears to exclusively affect buildings erected during approximately the last two decades. Based on observations by building owners, it is moreover noted that the efflorescence does not appear directly after construction but only after several years. However, as these observations of such delays are based on visual assessments, it is not clear whether persistent efflorescence indeed develops with a delay, or whether it is just a very slow process that goes unnoticed in its early stages.

\subsection{Composition analysis of persistent efflorescence}

To determine the efflorescence composition, efflorescence samples are collected and analysed, revealing four primary categories in the studied persistent efflorescence cases.

\subsubsection{Methodology}

Salt deposits were gently scraped from bricks in higher parts of the facades (above the $1.5 \mathrm{~m}$ height line), to exclude cases of salt accumulation due to rising damp. The collected samples were initially gently ground and then sieved through a $63 \mu \mathrm{m}$ sieve, to separate the salt deposit from sand grains inadvertently removed from the brick surfaces together with efflorescence. The deposit enriched fraction was ground even further, and then sprinkled over a silicon sample holder plate. To identify the minerals forming the efflorescence, the samples were analysed via the powder X-ray diffraction (XRD) method. The diffraction patterns were gathered with a Philips PW1830 diffractometer using $\mathrm{CuK} \alpha$ radiation $(45 \mathrm{kV}, 30 \mathrm{~mA})$. The standard $2 \theta$ scan range was 
Postprint: Jacek Chwast, Jelena Todorović, Hans Janssen, Jan Elsen, Gypsum efflorescence on clay brick masonry: Field survey and literature study, Construction and Building Materials, Volume 85, 15 June 2015, Pages 57-64, http://dx.doi.org/10.1016/j.conbuildmat.2015.02.094

taken to be $5-70^{\circ}$ with a step size of $0.02^{\circ} 2 \theta$ and a counting time of $1 \mathrm{~s}$. This methodology allows a qualitative estimation of the sample composition.

\subsubsection{Results}

Table 1 presents the results of sample analyses and case evaluations. Out of the four identified minerals - gypsum, calcite, hematite and quartz - only the former two are potential persistent efflorescence components. In most cases where gypsum is identified in a sample, it is present in a substantial amount compared to the other identified minerals. As it is not a raw brick component, it is clear that its accumulation at the surface of masonry is due to the efflorescence formation. Unlike for gypsum, the origin of calcite is uncertain, since there are several possible sources of calcite at the brick surface. Besides being recognised as a potential efflorescence forming mineral (Dow and Glasser 2003), calcite also naturally occurs in clays, and is moreover applied as a clay mix and brick sanding component. In most cases where calcite is identified in a sample, it is present in very low amounts, and its origin can therefore not be unambiguously determined. Hematite is a mineral which naturally occurs in clay and is also used as a brick pigment. The evaluation of XRD scans is hindered by the presence of quartz, which produces very intense and overlapping peaks.

Based on the sample mineral composition and visual observations, the investigated cases are divided into four efflorescence categories (Table 1). There are 13 cases categorised as gypsum efflorescence (G), where only gypsum is identified in substantial amounts in the collected samples. Only 1 case is assigned to the calcite efflorescence category (C), in which substantial amounts of calcite are accompanied by (very) low amounts of gypsum. The mixed efflorescence $(\mathrm{G}+\mathrm{C})$ category comprises 5 cases where both gypsum and calcite are identified in substantial amounts, and here we distinguish three further groups. The first group comprises 2 cases where the collected sample contains substantial amounts of both gypsum and calcite (FS16, FS34). The second group consists of 2 cases for which one of the collected samples is identified as gypsum efflorescence, while the sample collected from another area is identified as calcite efflorescence 
Postprint: Jacek Chwast, Jelena Todorović, Hans Janssen, Jan Elsen, Gypsum efflorescence on clay brick masonry: Field survey and literature study, Construction and Building Materials, Volume 85, 15 June 2015, Pages 57-64, http://dx.doi.org/10.1016/j.conbuildmat.2015.02.094

(FS28, FS32). In the last group we discern a single case, for which most of the building facades are affected with characteristic "lime leach” stains, accompanied by some areas covered with hazy gypsum efflorescence (FS26). For 9 cases the evaluation of samples is inconclusive, and they are assigned to the ambiguous (A) category. For these cases the origin of calcite in the efflorescence is uncertain, because of its very low amount in the sample or the use of sand/lime sanding in the brick; in 3 cases gypsum is found, but in very low amounts.

\subsection{Brick properties and persistent efflorescence}

In many cases the applied brick type is identified, which permits analysis of the relation between brick properties and persistent efflorescence. However, it was not possible to acquire data for the exact batches of bricks used for construction of the investigated buildings. We have thus used the available technical specifications declared by brick producers.

\subsubsection{Physical properties}

The brick technical specifications are available for 15 cases, yielding data about cold water absorption and initial rate of absorption (IRA). The values declared by producers are determined according to the EN 771-1 and EN 772-11 standards, respectively. They are represented in Figure 2, grouped along the specific efflorescence composition found for these 15 cases. This data analysis serves to check whether a correlation exists between the GE risk and the hygric properties, as reflected by IRA and cold water absorption, respectively. The IRA and water absorption values found for gypsum efflorescence cases are not limited to a specific range, but are rather spread over average values found for this brick type.

\subsubsection{Chemical properties}

Bricks may contain calcium sulphate in the form of anhydrite, which potentially can be a source of gypsum efflorescence. For some of the identified brick types data regarding the content of Na, 
Postprint: Jacek Chwast, Jelena Todorović, Hans Janssen, Jan Elsen, Gypsum efflorescence on clay brick masonry: Field survey and literature study, Construction and Building Materials, Volume 85, 15 June 2015, Pages 57-64, http://dx.doi.org/10.1016/j.conbuildmat.2015.02.094

$\mathrm{K}, \mathrm{Mg}$ and $\mathrm{SO}_{4}$ ions is available, as declared by the brick producers based on EN 772-5 (see Table 2). Those data are used here to estimate the amount of $\mathrm{Na}, \mathrm{K}$ and $\mathrm{Mg}$ sulphates and anhydrite present in the bricks, as well as to determine the amount of gypsum which can potentially be derived from anhydrite dissolution. The latter is simply calculated by subtracting the amount of $\mathrm{SO}_{4}$ bound in $\mathrm{Na}, \mathrm{K}$ and $\mathrm{Mg}$ sulphates from the total $\mathrm{SO}_{4}$ content, assuming that the rest of sulphates is bound as calcium sulphate and can be further recrystallized to gypsum. However, the EN 772-5 procedure is designed for the measurement of easily soluble salts and not of the hardly soluble anhydrite, and the calculated gypsum amounts may thus be conservative.

\subsection{Discussion}

The field study allows concluding that the persistent character of the analysed efflorescence cases can often be primarily attributed to slightly soluble gypsum. This agrees with the findings reported for the UK and the Netherlands, like most of the other outcomes of our field survey - visual appearance, recent occurrence, newly erected buildings, exposure to wind-driven rain, .... Of these, the grey-white visual appearance and the role of wind-driven rain render this gypsum efflorescence different from the gypsum weathering crusts often found on calcareous stones. These crusts are commonly black, frequently develop on sheltered sections, and are known to be formed via interaction with polluted air (Steiger, Charola, and Sterflinger 2011). These differences between the observed gypsum efflorescences and the gypsum weathering crusts corroborate that the gypsum efflorescence components are probably derived from the brick masonry itself: the grey-white appearance precludes interaction with polluted air, and the role of moisture transfer suggests sources inside the masonry.

The physico-chemical analysis provides more insight into the contribution of the bricks to the gypsum efflorescence. The cold water absorption and initial rate of absorption values obtained for the bricks in our efflorescence cases cover the range commonly found for this brick type. These physical parameters therefore do not seem to control the efflorescence. Instead, it appears that the 
Postprint: Jacek Chwast, Jelena Todorović, Hans Janssen, Jan Elsen, Gypsum efflorescence on clay brick masonry: Field survey and literature study, Construction and Building Materials, Volume 85, 15 June 2015, Pages 57-64, http://dx.doi.org/10.1016/j.conbuildmat.2015.02.094

exposure to wind-driven rain, rather than the moisture transfer properties itself, is a dominant factor. However, the significance of this conclusion is limited by the low number of analysed cases. Furthermore, the field survey indicates that even small amounts of gypsum may create distinct discolorations of the brick surface. The chemical analysis shows that these small amounts of gypsum may be derived from the minor amounts of anhydrite found in most of the studied bricks. While this does not prove the bricks are a definite source for the efflorescing gypsum, their potential contribution cannot be ruled out based on our observations.

\section{Literature review on gypsum efflorescence}

The field study has established the occurrence of gypsum efflorescence on brick masonry in Belgium, thus confirming and widening the earlier observations in the UK and the Netherlands (Bowler and Winter 1996; H. Brocken and Nijland 2004). As gypsum efflorescence has only come to the forefront in the last few decades, whereas brick masonry has been in use for many centuries, there are several open questions on the physico-chemical processes underlying this phenomenon. And even while the literature specifically dedicated to gypsum efflorescence is relatively limited, there are a number of studies from various other fields which can contribute to the understanding of gypsum efflorescence. These primarily relate to calcium sulphate sources, transport and crystallisation.

\subsection{Calcium sulphate sources}

Gypsum efflorescence at the surface of brick masonry requires a source of calcium sulphate in the masonry. The review below corroborates that calcium sulphate can be derived from ceramic brick and/or cement mortar. Calcium sulphate occurs in three distinct mineral forms: gypsum, bassanite and anhydrite, which are respectively the dihydrate $\left(\mathrm{CaSO}_{4} \cdot 2 \mathrm{H}_{2} \mathrm{O}\right)$, hemihydrate $\left(\mathrm{CaSO}_{4} \cdot 0.5 \mathrm{H}_{2} \mathrm{O}\right)$ and anhydrous $\left(\mathrm{CaSO}_{4}\right)$ forms. Both gypsum and anhydrite can be present in masonry, and it is 
Postprint: Jacek Chwast, Jelena Todorović, Hans Janssen, Jan Elsen, Gypsum efflorescence on clay brick masonry: Field survey and literature study, Construction and Building Materials, Volume 85, 15 June 2015, Pages 57-64, http://dx.doi.org/10.1016/j.conbuildmat.2015.02.094

hence important to distinguish between these two mineral forms. Under normal conditions gypsum is the stable calcium sulphate mineral form, explaining its presence in efflorescence. The conversion to anhydrite occurs at temperatures above $350{ }^{\circ} \mathrm{C}$ (Kuntze 2008).

\subsubsection{Brick as a calcium sulphate source}

Calcium sulphate in ceramic bricks may originate from the initial calcium sulphate in the clay mix, or may stem high-temperature reactions taking place during brick burning. In the former case the calcium sulphate persists during firing, since the typical brick burning temperatures of 900-1050 ${ }^{\circ} \mathrm{C}$ are below the calcium sulphate decomposition temperature of $1200-1300{ }^{\circ} \mathrm{C}$. In the latter case it is formed due to the reaction between calcium, bound as carbonate or more reactive oxide, with sulphates, formed by sulphide oxidation (e.g. pyrite decomposition) or directly available from the flue gasses (Vogt and Tatarin 2013). Independent of the reaction path, the final calcium sulphate mineral form present in the ceramic brick is anhydrite, given the high burning temperatures.

\subsubsection{Mortar as a calcium sulphate source}

Calcium sulphate is present in Portland cement to control the setting properties, it primarily reacts with tricalcium aluminate (C3A). A recent study has established that only a minor fraction of the sulphates can be absorbed by the CSH phase (Škapa 2009). The calcium sulphate and C3A interaction occurs in two stages: initially ettringite is formed, which then reacts to monosulphate. The extent of these two reactions depends on the ratio of calcium sulphate versus C3A (Taylor 1997). Originally, such added calcium sulphate was not considered as an efflorescence trigger, because ettringite and monosulphate are virtually insoluble (MacGregor Miller and Melander 2003). Synthetic ettringite does however undergo carbonation when exposed to $\mathrm{CO}_{2}$, decomposing back to gypsum and other minerals (Grounds, G Midgley, and V Novell 1988). Monosulphate is even less stable than ettringite, and hence more prone to decomposition (Gabrisová, Havlica, and Sahu 1991). Carbonated mortar is therefore a potential source of calcium sulphate, a hypothesis 
Postprint: Jacek Chwast, Jelena Todorović, Hans Janssen, Jan Elsen, Gypsum efflorescence on clay brick masonry: Field survey and literature study, Construction and Building Materials, Volume 85, 15 June 2015, Pages 57-64, http://dx.doi.org/10.1016/j.conbuildmat.2015.02.094

initially proposed by Brocken and Nijland (2004). However, the actual extent of mortar joint carbonation may counter this hypothesis, as reported concrete carbonation rates are rather slow, between 0.06-1.20 mm per year (Pade and Guimaraes 2007). Masonry joints do carbonate much faster though, as the permeable bricks provide more access to thin mortar joints. The complete carbonation of $12 \mathrm{~mm}$ thick cement mortar joints within two years is reported by Brocken et al. (2000).

\subsection{Calcium sulphate transport}

Apart from internal calcium sulphate sources, gypsum efflorescence moreover necessitates transport of calcium sulphate through the brick and mortar towards the surface. This section corroborates the possibilities for dissolution, diffusion and advection of calcium sulphate in masonry. In the subsequent section, the crystallisation of gypsum brought to the surface is discussed.

\subsubsection{Solubility and dissolution of calcium sulphate}

Contrary to other salts typically present in masonry, gypsum is slightly soluble at $0.015 \mathrm{~mol} / \mathrm{kg}$ at $25{ }^{\circ} \mathrm{C}$, which furthermore varies only minimally in the temperature range $0-25{ }^{\circ} \mathrm{C}$. The solubility of anhydrite, on the other hand, is somewhat higher at $0.019 \mathrm{~mol} / \mathrm{kg}$ at $25{ }^{\circ} \mathrm{C}$, but decreases strongly with increasing temperature. In relation to dissolution though, the reverse holds: in identical conditions, the dissolution rate of anhydrite is roughly two orders of magnitude smaller than the dissolution rate of gypsum (Jeschke and Dreybrodt 2002).

The presence of other solutes significantly alters the solubilities of gypsum and anhydrite: unlike ions (e.g. $\left.\mathrm{Na}^{+}, \mathrm{K}^{+}, \mathrm{Cl}\right)$ may increase it up to four times, whereas like ions $\left(\mathrm{Ca}^{2+}\right.$ and $\left.\mathrm{SO}_{4^{2}}\right)$ decrease it (Charola, Pühringer, and Steiger 2006). And while the dissolution of anhydrite, and its hydration to gypsum, is kinetically hindered, it does accelerate in the presence of specific salts. The most effective hydration accelerators are alkali sulphates, which convert anhydrite to gypsum via the double salt formation process (Freyer and Voigt 2003). 
Postprint: Jacek Chwast, Jelena Todorović, Hans Janssen, Jan Elsen, Gypsum efflorescence on clay brick masonry: Field survey and literature study, Construction and Building Materials, Volume 85, 15 June 2015, Pages 57-64, http://dx.doi.org/10.1016/j.conbuildmat.2015.02.094

\subsubsection{Diffusion and advection of calcium sulphate}

Generally, salts in porous materials can be transported when they are dissolved in water, by advection or/and diffusion. The former represents the bulk transport of water, carrying the salt ions with it, whereas the latter is the movement of ions within the water, driven by the salt concentration gradient. Experiments from Franke and Grabau (1998) demonstrate this diffusive and advective gypsum transport. Brick samples were fed at the bottom surface - with water, with a magnesium sulphate solution, and with a gypsum solution respectively - while evaporation was allowed at the top surface. After a few days, substantial reductions in the evaporation rates were noted for the samples fed with gypsum solution, although no salts appeared on the top surface. Further analysis confirmed gypsum crystallization just below the surface. This corroborates that even slightly soluble salts, like calcium sulphate, are substantially transported by diffusion and advection. Further support can be found in the subsequent water uptake experiments by Franke and Grabau (1998), during which the earlier evaporation surfaces were now exposed to water. It was noted that the capillary absorption was impeded in the first ten to twenty minutes, to then recover to the rate obtained for the samples formerly fed with pure water or magnesium sulphate solution.

\subsection{Calcium sulphate crystallization}

While calcium sulphate is thus transported by diffusion and advection, similarly to easily soluble salts, its crystallisation behaviour is however somewhat more particular. Typically, the location of salt crystallisation in a porous material is determined by the location of the drying front: drying at the surface is stated to result in crystallisation at the surface (efflorescence), while a drying front below the surface is said to lead to crystallisation within the material (subflorescence). This would lead one to expect that the same experimental conditions should result in the same crystallisation locations for different salts. The reverse is often observed in actual salts damage cases though, and 
Postprint: Jacek Chwast, Jelena Todorović, Hans Janssen, Jan Elsen, Gypsum efflorescence on clay brick masonry: Field survey and literature study, Construction and Building Materials, Volume 85, 15 June 2015, Pages 57-64, http://dx.doi.org/10.1016/j.conbuildmat.2015.02.094

this observation is further upheld by laboratory experiments demonstrating salt-specific crystallisation behaviour under well-defined laboratory conditions. For instance, Cardell et al. (2008) reported that efflorescence develops on limestone samples immersed in various salts solutions and their mixtures, but not for the gypsum solution for which only a limited subflorescence was identified. Based on field measurements, Charola et al. (2006) similarly concluded that gypsum tends to accumulate just below the surface for non-calcareous materials. It remains to be seen though whether this is also valid for the typical alternating wetting and drying of facade masonry.

\subsection{Discussion}

Both masonry components may hence be the source of gypsum efflorescence. The source is either originally present as anhydrite contained within the brick, or formed due to carbonation of the mortar joint. For the former, anhydrite as the source of gypsum efflorescence is questionable, since it is characterized by an exceptionally low dissolution rate. The carbonation of mortar, on the other hand, does not seem to be a limiting factor and actually supports the observed delay in the gypsum efflorescence. Gypsum efflorescence then proceeds through the processes of dissolution inside the masonry and transport to the surface of the masonry, the former induced by moisture supplied by wind-driven rain, the latter resulting from moisture drainage by surface drying.

Up to this point, the available knowledge offers some first insights into the physico-chemical processes underlying gypsum efflorescence. A first and the most important blow to the formulated argumentation is that both the sources and the transports have been active in ceramic brick and Portland cement based masonry since its original application, which does not allow explaining the only recent occurrence of gypsum efflorescence. On the other hand, the tendency of gypsum to crystallise under the surface additionally impairs the aforementioned reasoning chain. The general validity of the latter can however be questioned, due to limited data. The next section therefore investigates recent changes in masonry components and construction technology, to shed further light on the genesis of this problem. 
Postprint: Jacek Chwast, Jelena Todorović, Hans Janssen, Jan Elsen, Gypsum efflorescence on clay brick masonry: Field survey and literature study, Construction and Building Materials, Volume 85, 15 June 2015, Pages 57-64, http://dx.doi.org/10.1016/j.conbuildmat.2015.02.094

\section{Recent changes}

The argumentation put forward above falls short on two fronts: it does not explain the recent nature of gypsum efflorescence, nor does it clarify the surface crystallisation of gypsum. Gypsum efflorescence has sprung up during the last three decades, which apparently coincides with a number of major changes in material composition and construction technology. These mainly concern the chemical composition of cements and the use of mortar admixtures.

\subsection{Brick composition evolution}

To the authors' knowledge, the brick production technology in Belgium (and Europe) has not experienced significant changes in the last few decades. Bowler and Winter (1996) do indeed state a similar remark in relation to the UK. They verify this observation with an example of old and new constructions applying brick types that have been in use for over 100 years. Only the recent constructions are affected by gypsum efflorescence, while the older constructions do not suffer from such staining.

\subsection{Mortar composition evolution}

Masonry mortar composition, on the other hand, has evolved substantially over the last three decades, both in Belgium and in the UK. These changes mostly relate to the quality of binder and to the use of admixtures. In the UK cement/lime mortars have been gradually replaced by cement/air entrainer mixes. The presence of lime delays ettringite carbonation (Pajares, Martínez-Ramírez, and Blanco-Varela 2003; H. J. P. Brocken, van der Pers, and Larbi 2000), and this shift to cementonly-based mortars might therefore facilitate the release of sulphates due to mortar carbonation. In Belgium, cement-based mortar came into use in the 1950's; while cement/air entrainer mixes are preferred by masons nowadays (Hendrickx 2009). 
Postprint: Jacek Chwast, Jelena Todorović, Hans Janssen, Jan Elsen, Gypsum efflorescence on clay brick masonry: Field survey and literature study, Construction and Building Materials, Volume 85, 15 June 2015, Pages 57-64, http://dx.doi.org/10.1016/j.conbuildmat.2015.02.094

\subsubsection{Cement composition}

Bowler and Winter (1996) provide a thorough analysis of the more recent changes in the British cement industry. They conclude that the changes in fuel composition and production technology may lead to increased levels of sulphates in cement clinker. Nevertheless, their content is limited by national standards, and an analysis of the recent changes of those can benefit the evaluation. Bowler and Winter state that the sulphates level limits increased from 3\% to 3.5\% in the UK. It was accompanied by reducing and finally removing constraints for the C3A content. They hypothesize that, all in all, these changes might have led to a higher availability of sulphates in fresh mortar, which in turn could potentially be absorbed by bricks, to finally crystallise as the persistent efflorescence. To the knowledge of authors, the sulphate limits in Belgium in the last 3 decades have been fluctuating between $3.5 \%$ and $4.5 \%$, with no constraints on the C3A content for ordinary cements. A more recent trend is the addition of fly ash to Portland cement. Its presence results in faster and deeper carbonation, due to a lower content of portlandite, and formation of more carbonation-prone hydrates (McPolin, Basheer, and Long 2009).

\subsubsection{Use of admixtures}

Ettringite and monosulphate decomposition cannot solely explain the recent occurrences of gypsum efflorescence in Belgium. Both cement hydrates have been present in masonry mortars as long as cement has been used for their preparation and in the case of Belgium pure cement mortars have been commonly used since the 1950’s. Bowler and Winter (1996) thus considered the use of admixtures as one of the potential triggers for gypsum efflorescence. Gypsum efflorescence started to occur from the 1980’s onwards, what according to them coincides with the introduction of surfactant-based mortar admixtures, such as dedicated air entrainer and plasticizer products but also domestic detergents (Bowler and Winter 1996; Bowler and Winter 
Postprint: Jacek Chwast, Jelena Todorović, Hans Janssen, Jan Elsen, Gypsum efflorescence on clay brick masonry: Field survey and literature study, Construction and Building Materials, Volume 85, 15 June 2015, Pages 57-64, http://dx.doi.org/10.1016/j.conbuildmat.2015.02.094

1997). Already in 1957 Butterworth reported that air-entraining agents were frequently used in the UK, criticizing the use of domestic detergents (Butterworth 1957). In Belgium the first reports of gypsum efflorescence stem from the 1990’s, while industrial plasticizers and air entrainers were already introduced in the 1970's and 1980's. The use of mortar admixtures in Belgium is nowadays well appreciated, since it sometimes leads to the use of not officially certified products, dosed according to the user's experience (Hendrickx 2009).

Bowler and Winter (1997) conducted a series of wetting-drying tests on individual Fletton bricks to examine the influence of admixtures on gypsum efflorescence, including aqueous solutions of air entrainers and washing-up liquids. They noted that persistent efflorescence occurred only on the admixture-treated samples, contrasting with the unaffected reference samples. Since the bricks were known to contain elevated levels of anhydrite and the used substances did not contain soluble salts, they concluded that gypsum must have been derived from the bricks only. Similar results were obtained from experiments on masonry bins exposed to natural weathering for several years (Bowler and Sharp 1998). Bowler's experiments actually demonstrate that even anhydrite, being often considered as immobile and thus inert, can be activated as the source of gypsum efflorescence by admixtures. This generally confirms the experience of the British brick industry, as before 1980s no cases of persistent efflorescence were reported even though bricks with high anhydrite content were commonly used (Bowler and Fisher 1989; Butterworth 1957). The composition of the tested admixtures is based on surfactants, which can influence the formation of efflorescence in a number of ways. Bowler and Winter (1996) explained their observations through the surfactants effect on the pore solution mobility. Surfactants accumulate at the liquid-gas interface, modifying the wettability by reducing the liquid-stone contact angle, in turn enhancing liquid capillary transport and hence efflorescence formation (Rodriguez-Navarro, Doehne, and Sebastian 2000). Surfactants can also modify gypsum crystal growth, due to the preferential adsorption on crystal faces (Badens, Veesler, and Boistelle 1999). Finally, one can also reason that the Bowler and Winter (1997) experiments indicate an effect of surfactants on the 
Postprint: Jacek Chwast, Jelena Todorović, Hans Janssen, Jan Elsen, Gypsum efflorescence on clay brick masonry: Field survey and literature study, Construction and Building Materials, Volume 85, 15 June 2015, Pages 57-64, http://dx.doi.org/10.1016/j.conbuildmat.2015.02.094

dissolution and solubility of anhydrite in brick. The application of admixtures might therefore possibly explain the recent occurrence of gypsum efflorescence.

\subsection{Use of insulation}

Besides these internal changes in material composition and production, over the last few decades, modifications in the wall composition form an important external change. As reported by Bowler and Sharp (1998), the use of thermal insulation inside the cavity of masonry walls has significantly increased. It is assumed that walls become colder and wetter, hence potentially triggering gypsum efflorescence. However, the ways in which this may affect gypsum efflorescence, via impacts on the gypsum formation, transport and/or crystallization, remain unknown.

\section{Research questions on gypsum efflorescence}

Persistent staining of masonry surfaces by gypsum crystallisation is on the rise in the UK, in the Netherlands and in Belgium. This paper has therefore reported on a field survey and literature review on this particular efflorescence type. The field survey has resulted in a number of important observations. Gypsum efflorescence is a recent problem, which is restricted to facades constructed during the last few decades. It appears to develop in a slow or delayed way, since it is often only perceived a number of years after construction of the facade. The role of moisture in general, or wind-driven rain in particular, seems important, given that gypsum efflorescence exclusively affects facade sections with high exposure to wind-driven rain. The occurrence of gypsum efflorescence does appear to be unrelated to the physical or chemical properties of the brick. For instance, the analysis of bricks' declared technical properties did not reveal any significant dependency on the cold water absorption, initial rate of absorption or potential anhydrite contents of the bricks. All these observations agree with the earlier studies by Bowler and Winter (1996) and Brocken and Nijland (2004). And while research dedicated to gypsum 
Postprint: Jacek Chwast, Jelena Todorović, Hans Janssen, Jan Elsen, Gypsum efflorescence on clay brick masonry: Field survey and literature study, Construction and Building Materials, Volume 85, 15 June 2015, Pages 57-64, http://dx.doi.org/10.1016/j.conbuildmat.2015.02.094

efflorescence in particular is limited, a literature review of publications related to gypsum sources, transport and crystallisation has offered a number of insights. Both brick and mortar can be the source of calcium sulphates, via respectively the dissolution of anhydrite or the carbonation of ettringite. And despite their low solubility, calcium sulphates can be dissolved in the pore water, and transported via diffusion and advection processes. The literature review did however also reveal some bottle necks. All the mechanisms related to sources, transport and crystallisation are equally active in older cement-based masonry, contrary to the more recent nature of the gypsum efflorescence problem. Moreover, gypsum appears to exhibit a tendency for crystallisation below the surface, leading to subflorescence instead of efflorescence. In the last step hence, the recent changes experienced by masonry have been assessed. These mainly relate to the composition of binders, which might have caused the increased sulphate availability, and the application of admixtures, where use of surfactants has become common practice.

Nonetheless, many of the inferences articulated above remain hypothetical, which leads to the formulation of a number of research questions in relation to gypsum efflorescence. The first two relate to the calcium sulphate sources in masonry:

1. Is gypsum formed by carbonation of ettringite inside the mortar joint?

2. Is GE formed by mobilization of anhydrite from the brick?

The next concerns calcium sulphate crystallisation:

3. Can surface crystallisation be obtained by standard atmospheric excitation?

In relation to the recent occurrence, two more research questions are:

4. What is the impact of mortar admixtures on the calcium sulphate sources, transport and crystallisation?

5. What is the effect of cavity insulation on the calcium sulphate sources, transport and crystallisation? 
Postprint: Jacek Chwast, Jelena Todorović, Hans Janssen, Jan Elsen, Gypsum efflorescence on clay brick masonry: Field survey and literature study, Construction and Building Materials, Volume 85, 15 June 2015, Pages 57-64, http://dx.doi.org/10.1016/j.conbuildmat.2015.02.094

The future research should aim to design an experimental method allowing for reproducing gypsum efflorescence formation under laboratory conditions. The method may be based on the existing wick tests commonly used for salts crystallisation tests. However, these standard procedures do not simulate frequent surface wetting which might be of importance for the efflorescence formation. A validated method could be further adapted for evaluating brick and carbonated mortar as an efflorescence source and investigating the effect of admixtures or other parameters. This would be a starting point for improving brick or mortar formulations. Regardless of the apparent complexity of the problem, the efflorescence free old masonry buildings demonstrate that this problem can be avoided.

\section{Acknowledgements}

This work is supported by a funding of IWT Baekeland (No. 120193).

\section{References}

Badens, E., S. Veesler, and R. Boistelle. 1999. “Crystallization of Gypsum from Hemihydrate in Presence of Additives.” Journal of Crystal Growth 198-199, Part 1 (0): 704-9. doi:10.1016/S0022-0248(98)01206-8.

Bowler, G.K., and K. Fisher. 1989. "Soluble Salt Analysis and Indexation of Sulphation Risk.” Masonry International - Journal of the British Masonry Society 3 (2): 62-67.

Bowler, G.K., and R.H. Sharp. 1998. “Testing of Various Brick/mortar Combinations for Mortar Durability, Efflorescence Potential and Resistance to Rain Penetration.” In Proc Br Masonry Soc, 8:31-36.

Bowler, G.K., and N.B. Winter. 1996. “New Form of Salt Staining on External Masonry.” British Ceramic Transactions 95 (2): 82-86. 
Postprint: Jacek Chwast, Jelena Todorović, Hans Janssen, Jan Elsen, Gypsum efflorescence on clay brick masonry: Field survey and literature study, Construction and Building Materials, Volume 85, 15 June 2015, Pages 57-64, http://dx.doi.org/10.1016/j.conbuildmat.2015.02.094

Bowler, G.K., and N.B. Winter. 1997. "Investigation into Causes of Persistent Efflorescence on Masonry.” Masonry International 11 (1): 15-18.

Brocken, H., and T.G. Nijland. 2004. "White Efflorescence on Brick Masonry and Concrete Masonry Blocks, with Special Emphasis on Sulfate Efflorescence on Concrete Blocks.” Construction and Building Materials 18 (5): 315-23. doi:16/j.conbuildmat.2004.02.004.

Brocken, H.J.P., N.M. van der Pers, and J.A. Larbi. 2000. “Composition of Lime-Cement and AirEntrained Cement Mortar as a Function of Distance to the Brick-Mortar Interface: Consequences for Masonry.” Materials and Structures 33 (10): 634-46. doi:10.1007/BF02480603.

Butterworth, B. 1957. "Efflorescence and Staining of Brickwork.” The Brick Bulletin 3 (5): 3-10. Cardell, C., D. Benavente, and J. Rodríguez-Gordillo. 2008. "Weathering of Limestone Building Material by Mixed Sulfate Solutions. Characterization of Stone Microstructure, Reaction Products and Decay Forms.” Materials Characterization 59 (10): 1371-85. doi:10.1016/j.matchar.2007.12.003.

Charola, A.E., J. Pühringer, and M. Steiger. 2006. “Gypsum: A Review of Its Role in the Deterioration of Building Materials.” Environmental Geology 52 (2): 339-52. doi:10.1007/s00254-006-0566-9.

Dow, C, and F.P Glasser. 2003. “Calcium Carbonate Efflorescence on Portland Cement and Building Materials.” Cement and Concrete Research 33 (1): 147-54. doi:10.1016/S00088846(02)00937-7.

EN 771-1. 2011. “Specification for Masonry Units - Part 1: Clay Masonry Units.”

EN 772-11. 2000. "Methods of Test for Masonry Units - Part 11: Determination of Water Absorption of Aggregate Concrete, Manufactured Stone and Natural Stone Masonry Units due to Capillary Action and the Initial Rate of Water Absorption of Clay Masonry Units.” EN 772-5. 2002. "Methods of Test for Masonry Units - Part 5: Determination of the Active Soluble Salts Content of Clay Masonry Units.” 
Postprint: Jacek Chwast, Jelena Todorović, Hans Janssen, Jan Elsen, Gypsum efflorescence on clay brick masonry: Field survey and literature study, Construction and Building Materials, Volume 85, 15 June 2015, Pages 57-64, http://dx.doi.org/10.1016/j.conbuildmat.2015.02.094

Franke, L., and J. Grabau. 1998. “Influence of Salt Content on the Drying Behavior of Brick.” In Conservation of Historic Brick Structures, Baer N. S., Fitz S, Livingston R.A., 59-68. Donhead.

Freyer, D., and W. Voigt. 2003. “Crystallization and Phase Stability of CaSO4 and CaSO4 Based Salts.” Monatshefte Für Chemie / Chemical Monthly 134 (5): 693-719. doi:10.1007/s00706-003-0590-3.

Gabrisová, A., J. Havlica, and S. Sahu. 1991. “Stability of Calcium Sulphoaluminate Hydrates in Water Solutions with Various pH Values.” Cement and Concrete Research 21 (6): 102327. doi:10.1016/0008-8846(91)90062-M.

Grounds, T., H. G Midgley, and D. V Novell. 1988. “Carbonation of Ettringite by Atmospheric Carbon Dioxide.” Thermochimica Acta 135: 347-52. doi:10.1016/0040-6031(88)87407-0.

Hendrickx, R. 2009. “The Adequate Measurement of the Workability of Masonry Mortar”. Ph.D. thesis, KU Leuven.

Jeschke, A.A., and W. Dreybrodt. 2002. "Pitfalls in the Determination of Empirical Dissolution Rate Equations of Minerals from Experimental Data and a Way out: An Iterative Procedure to Find Valid Rate Equations, Applied to Ca-Carbonates and -Sulphates.” Chemical Geology 192 (3-4): 183-94. doi:10.1016/S0009-2541(02)00135-3.

Kuntze, R.A. 2008. “4. Basic Properties.” In Gypsum: Connecting Science and Technology, 2336. R. A. K. Associates.

MacGregor Miller, F., and M.J. Melander. 2003. “Efflorescence - a Synopsis of the Literature.” In Proceedings, the Ninth North American Masonry Conference, 11-24. Masonry Society. McPolin, D., P. Basheer, and A. Long. 2009. "Carbonation and pH in Mortars Manufactured with Supplementary Cementitious Materials.” Journal of Materials in Civil Engineering 21 (5): 217-25. doi:10.1061/(ASCE)0899-1561(2009)21:5(217).

Pade, C., and M. Guimaraes. 2007. “The CO2 Uptake of Concrete in a 100 Year Perspective.” Cement and Concrete Research 37 (9): 1348-56. doi:10.1016/j.cemconres.2007.06.009. 
Postprint: Jacek Chwast, Jelena Todorović, Hans Janssen, Jan Elsen, Gypsum efflorescence on clay brick masonry: Field survey and literature study, Construction and Building Materials, Volume 85, 15 June 2015, Pages 57-64, http://dx.doi.org/10.1016/j.conbuildmat.2015.02.094

Pajares, I., S. Martínez-Ramírez, and M.T. Blanco-Varela. 2003. “Evolution of Ettringite in Presence of Carbonate, and Silicate Ions.” Cement and Concrete Composites 25 (8): 86165. doi:10.1016/S0958-9465(03)00113-6.

Rodriguez-Navarro, C., E. Doehne, and E. Sebastian. 2000. “Influencing Crystallization Damage in Porous Materials through the Use of Surfactants: Experimental Results Using Sodium Dodecyl Sulfate and Cetyldimethylbenzylammonium Chloride.” Langmuir 16 (3): 94754. doi:10.1021/la990580h.

Škapa, R. 2009. “Optimum Sulfate Content of Portland Cement”. Ph.D. thesis, Aberdeen University.

Steiger, M., A.E. Charola, and K. Sterflinger. 2011. "Weathering and Deterioration.” In Stone in Architecture, edited by S. Siegesmund and R. Snethlage, 227-316. Berlin, Heidelberg: Springer Berlin Heidelberg.

Steiger, M., and A. Heritage. 2012. "Modelling the Crystallisation Behaviour of Mixed Salt Systems: Input Data Requirements.” In 12th International Congress on the Deterioration and Conservation of Stone.

Taylor, H.F.W. 1997. “6.5.2 Reaction of C3A with Water in the Presence of Calcium Sulfate.” In Cement Chemistry, 182-83. Thomas Telford.

Vogt, R., and A. Tatarin. 2013. “Lime Spalls and Efflorescence from Lime and Gypsum on Heavy Clay Products.” Ziegelindustrie International, no. 7-8: 29-41. 


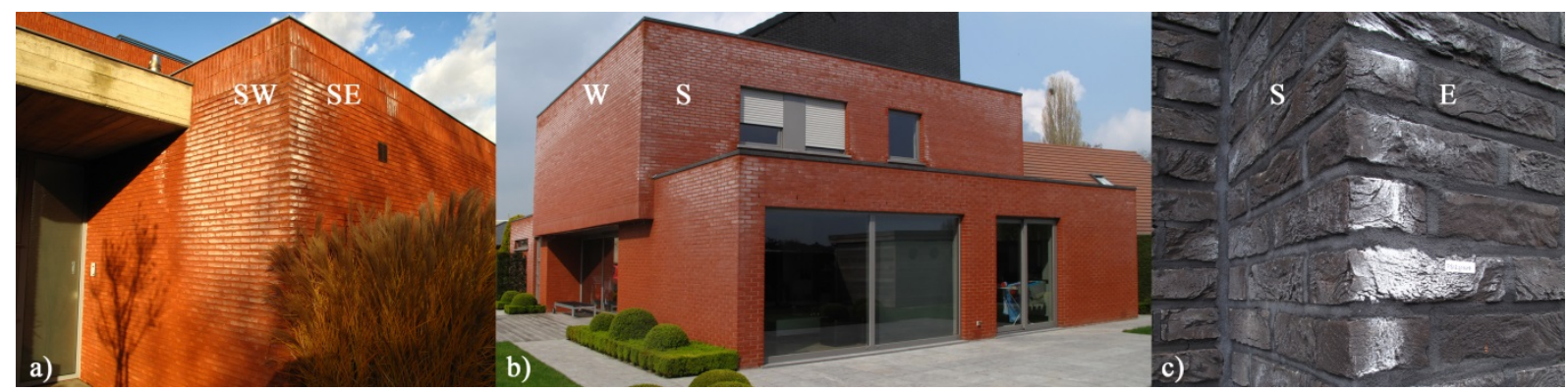

Figure 1 Efflorescence develops preferentially on a), b) facades and c) edges which are exposed to an intensified action of rain and wind. The capital letters indicate orientation of the facades: $S$ - south, $W$ - west, E - east.

Table 1 Evaluation of the analysed persistent efflorescence field study (FS) cases. For each identified mineral: $G$ - gypsum, $C$ - calcite, $H$ - hematite and $Q$-quartz its relative content is approximated: +++ dominantly present, ++ present, + present in low amounts, ? possibly present, - not identified. Each case is categorised as gypsum $(G)$, calcite $(C)$, mixed $(G+C)$ or ambiguous (A) efflorescence.

\begin{tabular}{|c|c|c|c|c|c|c|c|c|c|c|c|}
\hline \multirow{2}{*}{$\begin{array}{c}\text { Case } \\
\mathrm{n}^{\circ}\end{array}$} & \multicolumn{4}{|c|}{ Composition (XRD) } & \multirow{2}{*}{$\begin{array}{c}\text { Case } \\
\text { evaluation }\end{array}$} & \multirow{2}{*}{$\begin{array}{c}\text { Case } \\
n^{\circ}\end{array}$} & \multicolumn{4}{|c|}{ Composition (XRD) } & \multirow{2}{*}{$\begin{array}{c}\text { Case } \\
\text { evaluation }\end{array}$} \\
\hline & $\mathrm{G}$ & $\mathrm{C}$ & $\mathrm{H}$ & Q & & & $\mathrm{G}$ & $\mathrm{C}$ & $\mathrm{H}$ & Q & \\
\hline FS01 & ++ & + & - & +++ & $\mathrm{G}$ & FS23 & +++ & + & - & + & $\mathrm{G}$ \\
\hline \multirow{2}{*}{ FS02 } & - & + & - & +++ & \multirow{2}{*}{ A } & FS24 & +++ & + & - & + & $\mathrm{G}$ \\
\hline & - & - & - & +++ & & \multirow{2}{*}{ FS25 } & - & + & + & +++ & \multirow{2}{*}{ A } \\
\hline \multirow{2}{*}{ FS03 } & + & + & - & +++ & \multirow{2}{*}{ G } & & - & + & - & +++ & \\
\hline & +++ & + & - & - & & \multirow{2}{*}{ FS26 } & - & +++ & - & +++ & \multirow{2}{*}{$\mathrm{G}+\mathrm{C}$} \\
\hline FS07 & - & + & - & +++ & A & & +++ & - & - & ++ & \\
\hline FS08 & ++ & + & - & +++ & $\mathrm{G}$ & FS27 & +++ & + & + & ++ & $\mathrm{G}$ \\
\hline FS10 & +++ & ? & - & ++ & $G$ & \multirow{2}{*}{ FS28 } & - & ++ & + & +++ & \multirow{2}{*}{$\mathrm{G}+\mathrm{C}$} \\
\hline FS11 & + & ++ & - & +++ & A & & +++ & + & - & +++ & \\
\hline FS13 & - & ++ & - & +++ & A & \multirow{2}{*}{ FS29 } & +++ & ? & - & +++ & \multirow{2}{*}{$\mathrm{G}$} \\
\hline FS14 & - & + & - & +++ & A & & +++ & ? & - & ++ & \\
\hline FS16 & +++ & +++ & + & +++ & $\mathrm{G}+\mathrm{C}$ & FS30 & +++ & ? & - & + & $\mathrm{G}$ \\
\hline FS17 & - & + & - & +++ & A & \multirow{2}{*}{ FS31 } & + & + & - & +++ & \multirow{2}{*}{ A } \\
\hline FS18 & +++ & + & - & +++ & G & & - & ++ & + & +++ & \\
\hline FS19 & +++ & + & - & +++ & $\mathrm{G}$ & \multirow{2}{*}{ FS32 } & + & ++ & - & +++ & \multirow{2}{*}{$\mathrm{G}+\mathrm{C}$} \\
\hline FS20 & +++ & + & - & + & $\mathrm{G}$ & & +++ & + & - & +++ & \\
\hline FS21 & +++ & ? & - & +++ & $G$ & FS33 & + & + & - & +++ & A \\
\hline FS22 & + & ++ & - & +++ & $\mathrm{C}$ & FS34 & ++ & ++ & + & +++ & $\mathrm{G}+\mathrm{C}$ \\
\hline
\end{tabular}


Postprint: Jacek Chwast, Jelena Todorović, Hans Janssen, Jan Elsen, Gypsum efflorescence on clay brick masonry: Field survey and literature study, Construction and Building Materials, Volume 85, 15 June 2015, Pages 57-64, http://dx.doi.org/10.1016/j.conbuildmat.2015.02.094

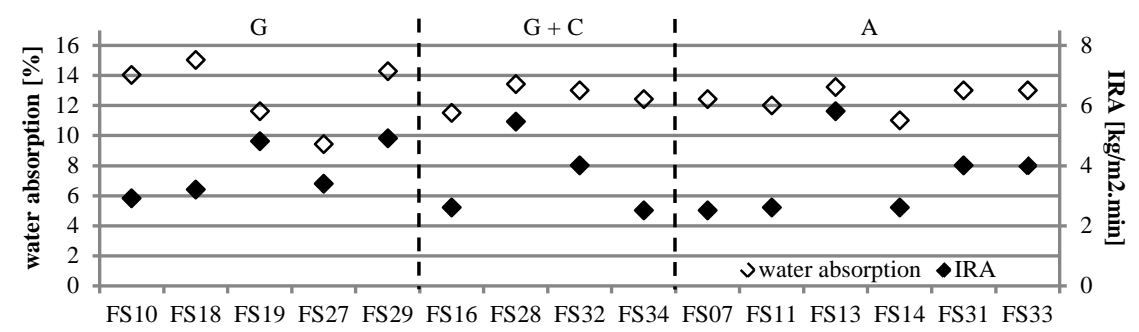

Figure 2 Water absorption and the initial rate of absorption (IRA) of the identified brick types. The efflorescence categories are indicated above the graph: $G$ - gypsum efflorescence, $G+C-$ gypsum and calcite efflorescence, $A$ - ambiguous cases.

Table 2 Chemical characteristics of the identified brick types.

\begin{tabular}{|c|c|c|c|c|c|c|c|c|c|c|c|c|c|}
\hline \multirow{2}{*}{$\begin{array}{c}\text { Case } \\
\mathrm{n}^{\circ}\end{array}$} & \multirow[t]{2}{*}{ Group } & \multicolumn{4}{|c|}{ Ion content [wt\%] } & \multirow{2}{*}{$\begin{array}{c}\text { Gypsum / } \\
\text { brick [g] }\end{array}$} & \multirow{2}{*}{$\begin{array}{c}\text { Case } \\
\mathrm{n}^{\circ}\end{array}$} & \multirow[t]{2}{*}{ Group } & \multicolumn{4}{|c|}{ Ion content [wt\%] } & \multirow{2}{*}{$\begin{array}{l}\text { Gypsum/ } \\
\text { brick [g] }\end{array}$} \\
\hline & & $\mathrm{SO}_{4}$ & $\mathrm{Na}$ & $\bar{K}$ & $\mathrm{Mg}$ & & & & $\mathrm{SO}_{4}$ & $\mathrm{Na}$ & $\bar{K}$ & $\mathrm{Mg}$ & \\
\hline FS10 & G & 0.248 & 0.001 & 0.001 & 0.000 & 7.16 & FS07 & A & 0.014 & 0.003 & 0.002 & 0.001 & 0.19 \\
\hline FS11 & A & 0.172 & 0.001 & 0.001 & 0.000 & 4.91 & FS14 & $\mathrm{A}$ & 0.014 & 0.003 & 0.002 & 0.001 & 0.19 \\
\hline FS13 & $\mathrm{A}$ & 0.056 & 0.001 & 0.001 & 0.001 & 1.44 & FS34 & $\mathrm{G}+\mathrm{C}$ & 0.014 & 0.003 & 0.002 & 0.001 & 0.19 \\
\hline FS29 & $G$ & 0.044 & 0.001 & 0.000 & 0.001 & 1.16 & FS28 & $\mathrm{G}+\mathrm{C}$ & 0.003 & 0.001 & 0.000 & 0.000 & 0.00 \\
\hline FS18 & G & 0.020 & 0.002 & 0.001 & 0.003 & 0.28 & & & & & & & \\
\hline
\end{tabular}

